ORGANISATIONAL MATTERS

\title{
Re-thinking accountability: trust versus confidence in medical practice
}

\author{
K Checkland, M Marshall, S Harrison
}

See editorial commentary, $\mathrm{p} 88$

Qual Saf Health Care 2004;13:130-135. doi: 10.1136/qshc.2003.009720

In seeking to prevent a reoccurrence of scandals such as that involving cardiac surgery in Bristol, the UK government has adopted a model of regulation that uses rules and surveillance as a way of both improving the quality of care delivered and increasing confidence in healthcare institutions. However, this approach may actually act to reduce confidence and trust while also reducing the moral motivation of practitioners. Accountability in health care is discussed, and it is suggested that openness about the difficult dilemmas that arise when practitioners have a duty to be accountable to more than one audience may be an alternative means of restoring trust. A greater emphasis on the sharing of information between individual health professionals and their patients would increase trust and would allow patients to hold their doctors to account for the quality of care they receive. Concentrating more on developing trust by the sharing of information and less on the futile search for complete confidence in systems and rules may improve the quality of care delivered while also nurturing the moral motivation of professionals upon which the delivery of high quality health care depends.

See end of article for authors' affiliations

Correspondence to: Dr K Checkland, National Primary Care Research and Development Centre, University of Manchester, Oxford Road, Manchester M13 9PL, UK;

katherine.checkland@ man.ac.uk

Accepted for publication 23 February 2004
1 $\mathrm{n}$ recent years commentators in the UK and elsewhere have called repeatedly for the medical profession to be more accountable for what they do. ${ }^{1-5}$ These calls have arisen in a climate that has been shaped by scandals and healthcare disasters such as the inquiry into poor standards of cardiac surgery in Bristol in the UK, the scandal over inadequate screening of blood products in France, and the death of a journalist in the USA from a chemotherapy dosage error that resulted in a fatal overdose. They reflect a widespread concern that repeated scandals have fatally undermined the trust of individuals in healthcare systems. ${ }^{6}$ These highly publicised scandals have occurred at the same time as a rise in consumerism, ${ }^{7-9}$ and the development of a society that is both more exposed to risks ${ }^{10}$ and less tolerant of those risks. Together, these things have put pressure on governments to "do something" about the regulation of the medical profession. ${ }^{11}$ The UK government has gone further than any other in its attempt to institutionalise the concept of accountability. This paper draws on what is happening in the
UK to explore the concepts of trust, confidence, and accountability and discusses the potential effects of the remedies adopted in the UK on quality of care in its widest sense. Openness, and its role in re-establishing trust, will be considered.

\section{ACCOUNTABILITY}

What does it mean to be "accountable"? The Oxford English Dictionary (http://athens.oed. com) defines accountability as "liability to give an account of and answer for discharge of duties or conduct". This definition implies three things.

Firstly, being "liable to give an account of" implies an audience; the question arises: "accountable to whom?" It is here that notions of accountability become complicated. The Chief Medical Officer in the UK, writing for an audience of qualified medical practitioners, identifies a long list of those to whom medical practitioners should feel themselves to be accountable. ${ }^{1}$ These include patients and their advocates, employers, professional regulatory bodies, the courts, elected politicians, and the wider general public (as well as some that might be said to be arguable such as the media). However, it has been pointed out that "the aims and desires of the groups to whom professionals are accountable may not be compatible at all times". ${ }^{2}$ Thus, while in systems in which public money is invested in health services doctors will be accountable to elected politicians for the prudent use of that money, this may conflict with the very reasonable desire of individual patients for the most expensive treatments available, however slim the chance of success. Similarly, while accountability to the general public for the improvement of public health might require some coercion in areas such as vaccination or smoking, this will conflict with the accountability to individuals that forms the bedrock of many doctors' personal credo. In some systems accountability to employers may conflict with accountability to individuals. For example, in Health Maintenance Organisations accountability to the organisation for the efficient use of resources may put pressure on health professionals to provide care that they feel is less than the optimum. Conversely, in a system where the patient pays, the responsibility to maximise income may result in unnecessary procedures being performed.

Secondly, to be accountable one must give "an account". Such an account could take many forms, the most obvious distinction being between a numerical quantitative account and a more discursive qualitative account. If healthcare 
professionals are to be more accountable, the type of account that is held to be valid must be considered.

Thirdly, the definition of accountability given above implies that the "audience" has some power; to be truly accountable to someone, that person (or body) should be able to apply sanctions should the account rendered be unacceptable. In health care the list of those with powers of sanction is considerably shorter than the list of those to whom accounts might be given. Thus, patients generally have few sanctions short of changing their doctor or taking individual practitioners to court. The former is easier in some systems than in others, ${ }^{12}$ and the latter is both expensive and time consuming. Professional bodies such as the General Medical Council in the UK do have available sanctions but these have been widely perceived as acting to protect doctors rather than patients. Paradoxically, in western-style democracies governments have generally had few sanctions against individual practitioners, and it may be that the new contract for family doctors currently being implemented in the UK that emphasises behaviour change via financial incentives is recognition of this fact.

\section{Legislating for accountability}

In the UK there have been a series of widely reported healthcare scandals in the past few years. These have included the suspension from the medical register of paediatric cardiac surgeons from Bristol following an inquiry into poor standards of care, ${ }^{13}$ the revelation that children's organs had been removed and retained without their parents' consent during post mortem examinations at Alder Hey Hospital in Liverpool, ${ }^{14}$ and the murder by Dr Harold Shipman of more than 200 of his patients (box 1). ${ }^{15-17}$ These and other failures, alongside a growing consumerism and the erosion of the traditional gap in knowledge between doctors and patients, ${ }^{18}$ have formed the background to the reform of the UK health service instituted by the incoming Labour government in 1997. In a succession of government papers a "new vision" for the NHS was set out, with "quality" and "accountability" repeatedly invoked as the guiding principles upon which the changes are based. ${ }^{19-22}$

The lynchpin of the quality agenda was a new concept labelled clinical governance, ${ }^{23}$ described by Scally and Donaldson $^{24}$ as "the main vehicle for continuously improving the quality of patient care and developing the capacity of the NHS in England to maintain high standards (including dealing with poor professional performance)". There has been criticism from academics ${ }^{25-28}$ of the failure to clearly explain either what clinical governance is (the official definition is that it is a framework for quality improvement that operates by "creating an environment in which excellence will flourish" ${ }^{\prime 20}$ ) or how it differs from the generally accepted duty of professionals in any sphere to strive reflexively to improve the work that they do. ${ }^{29}$ In spite of this criticism, health providers across the UK have appointed clinical governance leads, set up committees, and generated a great deal of activity in the name of clinical governance.

In addition to this catch-all obligation on all UK health workers to strive to continually improve the quality of their services, ${ }^{23}$ the legislation that followed the consultation documents established a new inspection body, the Commission for Health Improvement (now amalgamated with parts of the Audit Commission and the National Care Standards Commission to become the Commission for Healthcare Audit and Inspection (CHAI)). Furthermore, the National Institute for Clinical Excellence (NICE) was given the task of providing guidance about appropriate treatments that individual practitioners and hospitals are expected to follow, ${ }^{30}$ and annual practitioner appraisal and regular
Box 1 Scandals affecting health care in the UK

Bristol

- The death rates from paediatric cardiac surgery at Bristol Royal Infirmary were found to be higher than in equivalent units. Following a public inquiry, some of those involved were struck off the medical register and new systems were put in place to monitor quality of care in surgical units.

\section{Alder Hey}

- Organs were removed at post mortem examination from children who died at Alder Hey hospital in Liverpool without their parent's consent. Following a public inquiry, compensation was paid and systems have been put in place to tighten up the rules about informed consent.

\section{Dr Shipman}

- Dr Harold Shipman was convicted in 2000 of the murder of 15 of his patients. A subsequent inquiry found that the number of patients murdered by him was probably more than 200. An ongoing inquiry is addressing the procedures surrounding death and cremation certification.

certification of fitness to practice were introduced. National Service Frameworks, specifying not only the appropriate evidence-based clinical care for patients with conditions such as heart disease and diabetes but also the best models of service whereby that care should be delivered (based upon expert opinion rather than evidence), were announced and are being published in a rolling programme. Finally, the performance of healthcare providers was to be measured against targets and stars awarded as a result. Thus, in response to the perceived loss of public trust in healthcare institutions, ${ }^{6}$ the UK government has introduced a comprehensive package of measures designed to increase the accountability of both individual practitioners and institutions.

\section{CONFIDENCE VERSUS TRUST}

These changes represent a shift away from accountability based on the idea of professionalism and "reflective practice" ${ }^{\prime 29}$ towards accountability based on surveillance and rules. Writing in the context of similar changes in the field of social work in the UK, Smith ${ }^{31}$ distinguishes between what she labels "confidence" and "trust", and argues that emphasis upon surveillance and rules shows a preoccupation with the former over the latter. According to Smith, confidence governs "those everyday interactions where we assume relative certainty and security provided by abstract systems-role expectations, commonly shared norms, expert knowledge, systems of regulation, law and so on", while trust is necessary where there is vulnerability or uncertainty, and tends to arise between individuals rather than between individuals and systems. Harrison and $\mathrm{Smith}^{32}$ argue that, while lip service is paid in government documents to the notion of trust, "policy developments in health and social care-the modernisation agenda-are informed by an intention to found organisational and professional practice on confidence". In a subsequent paper these authors suggest 
that "clinical governance is a mechanism for controlling the health professions, most obviously doctors", and that NICE, CHI, National Service Frameworks, and clinical governance have created a system that is "much more rule-constrained and rule-governed than before."

\section{Dysfunctional consequences of relying on "confidence" rather than "trust"}

Harrison and Smith set out what they believe are the consequences of a reliance on measures to promote confidence over trust. Firstly, they point to what they call the "transaction costs" of this shift. These include the cost of funding the clinical governance and performance framework for the NHS, possible increases in litigation when trust between individual practitioners and their patients is lost, and less visible but nonetheless real costs for practitioners associated with loss of flexibility that occurs when practice is governed by guidelines and rules. Secondly, they argue that emphasis on confidence obscures the essential uncertainty associated with much diagnosis and treatment. This, they contend, may lead to unrealistic expectations from service users, reducing confidence and so leading to further attempts at regulation and control. The ultimate result of this may be an "abdication by service providers of any personal investment in service improvement". Finally, they argue that, while policy documents "are full of morally loaded imperatives", basing accountability on confidence and regulation diminishes the role of morality in the relationship between service providers and users. They conclude that confidence alone cannot provide answers to the morally difficult dilemmas that characterise health and social care, and that increasing the role of surveillance, measurement and rules may have the effect of reducing what might be called the "moral motivation" of practitioners.

There is some evidence in practice that concentrating upon measures to increase confidence does have dysfunctional consequences. The most obvious of these is the potential for the distortion that occurs when particular performance targets are privileged above all else, with the consequent de-prioritisation of aspects of practice that are not being measured.$^{34}$ When detailed targets were set for waiting times in A\&E departments in the UK, it is claimed that managers resorted to a variety of dubious strategies to meet the targets such as canceling routine operations, inappropriate admissions to hospital, and rapid transfers out of A\&E departments to avoid breaching the target. ${ }^{35}$ Furthermore, Power ${ }^{36}$ argues that reliance upon formal audits of performance will, by implying distrust in professionals, foster and create that distrust. The "gaming"33 that then occurs as participants strive to meet targets may result in dishonest behaviour that reduces trust still further. For example, managers at the Good Hope Hospital in Birmingham reported spurious waiting time figures in a bid to improve their star rating. ${ }^{37}$ There is also a danger that catch-all ill defined concepts such as clinical governance develop a ritualistic quality that has little to do with real quality improvement (Power calls this the replacement of real reflection with "formalized rituals of accounting and verification"). It is possible that, if documents refer to clinical governance and clinical governance leads are appointed, there is a danger that this activity will be mistaken for real improvements in quality of care. There are also pitfalls associated with measurement of performance as the prime mechanism for bringing about improvement in healthcare systems. The development of performance league tables emphasises competition and oversight at the expense of mutuality, and this risks a failure to take into account aspects of performance that matter most to patients. $^{38}$

\section{OPENNESS AS AN ALTERNATIVE ROUTE TO ACCOUNTABILITY?}

Is there an alternative to the mechanistic and highly regulated approach to accountability seen in the UK? As traditional deference towards professionals has been eroded by scandal, increased consumerism, and the information revolution, ${ }^{718}$ there have been calls for a new kind of accountability as one way of engaging with these difficult problems. Donaldson ${ }^{1}$ states that "new and explicit forms of accountability have been required and captured in the concept of clinical governance". In a further exploration of these themes as they apply to primary care, Allen ${ }^{2}$ discusses a wide range of possible focuses of accountability. However, she concludes rather pessimistically that, in the absence of significant increases in funding for this work, primary care professionals in the UK will have to concentrate on accountability to central government as well as the development of robust processes such as explicit systems to deliver care, neglecting (in the short term) what she calls "downward accountability" to patients. It is these mechanisms of accountability to central government and reliance upon systems of care such as guidelines and frameworks that have been criticised for neglecting trust and relying too heavily on the futile quest for complete confidence. How, then, can these problems be addressed? We think that a new form of accountability is indeed needed, but not one that relies so heavily on measures designed to increase confidence at the expense of trust.

\section{Accountable to whom?}

As discussed above, to be accountable implies an audience, and it may be that the needs and wishes of the multiple audiences to whom medical practitioners are accountable will be incompatible. ${ }^{2}$ How can these different obligations be reconciled? Glossing over such conflicts under an umbrella term such as "clinical governance" is an inadequate response; bringing them into the open may be a possible solution. There have been calls for greater openness as a mechanism to drive forward quality of care, but these have tended to focus on openness about performance rather than openness about difficult decisions. ${ }^{12}$ If the public are made aware of the conflicts that exist, for example, between the need for a cash limited service to pursue value for money and the individual good represented by the need of a particular patient for an expensive medication, what will be the impact on both confidence and trust? Hadorn and Holmes ${ }^{39}$ have claimed that airing these dilemmas and setting explicit criteria for the provision of surgical treatment for coronary heart disease in New Zealand had positive consequences for the confidence of individuals in the system. However, Coast $t^{40}$ argues that such explicit discussion of difficult issues has the potential to undermine both individuals' trust in their healthcare providers and public confidence in the system as a whole, and that the social solidarity required to sustain a publicly funded national health service would suffer as a result.

In the UK, although cost effectiveness was included in the terms of reference of NICE, politicians shied away from acknowledging that the decisions made by NICE about whether or not a particular treatment would be funded can never be wholly based on clinical criteria and divorced from political decision making. ${ }^{41}$ Would an open acknowledgement of these things increase trust or confidence, and is it possible to incorporate more than the views and values of a vociferous minority? A number of experiments involving the public in priority setting in the health service have been performed in the UK. There is general agreement that it is possible-given time, money and information-to develop a meaningful dialogue with representative groups of citizens about difficult 
issues. ${ }^{42}{ }^{43}$ However, there is also a near universal failure to take the next step and to base decisions upon the results of that dialogue. While those who have taken part in such discussions report changes in their attitudes and understanding of the issues involved, it is not clear what, if any, impact this kind of initiative can have on those who are not involved directly.

At a micro level, would greater openness about the conflicts associated with being accountable to multiple audiences improve trust between doctors and their patients? There can be no doubt that the open sharing of information between health professionals and their clients would improve the relationship between them and so probably increase trust. Indeed, it has been argued that this kind of relationship building is essential in a situation where, even in the presence of good quality evidence and best practice guidelines, the effect of a particular treatment on individuals is essentially unpredictable and uncertain. ${ }^{31}$ In the presence of this uncertainty, trust is vital and openness about the conflicting pressures may be one way of building this. However, the reluctance to be open about priority setting exhibited by healthcare organisations suggests that there is a fear that the release of such information would dent confidence in institutions. Whether this fear is justified and how far any such loss of confidence in institutions can be offset by greater trust in individuals needs to be debated.

\section{What kind of account?}

There are many different types of account that can be rendered to an audience. The most obvious distinction is between a quantitative measurement of performance and a qualitative account of one's work. Much of the current discussion about transparency and accountability focuses on the former, arguing for the publishing of numerical performance data to allow individual consumers of health care to make decisions about where and by whom they wish to be seen. The star system of rating hospitals and other healthcare providers is an example of this quantitative approach. While acknowledging that there is some value in making some of the information used to award the stars available, we would argue that, in common with school league tables, it could result in the development of a crude and potentially misleading picture. Valuing qualitative accounts as highly as quantitative ones may guard against this, and we would argue that those advocating openness about performance should pay attention to ways of evaluating such accounts and incorporating them into judgements about performance.

\section{Held to account: who can apply sanctions?}

Confidence producing measures to improve accountability involve appraisal, regular assessment of fitness to practise, and increased powers to remove offenders from practice. However, it is generally agreed that Dr Shipman would have passed the current form of appraisal in the NHS with ease, and no system of detecting and dealing with failure can be said to be without flaws. ${ }^{16}$ Relying on systems to induce confidence that then fail runs the risk of further alienating those who use the system.

One approach to this problem may be to increase the possibility of individuals applying sanctions by, for example, making it easier to change doctors. However, this kind of approach favours the articulate and the mobile-those who can afford to travel to a different doctor or hospital or who can afford to change their health maintenance organisation can do so, while those who are uninsured or for whom travel is difficult cannot.

Here again, greater openness may have a role to play. While it is difficult literally to give the power of holding to account to patients, reducing the imbalance of power between professionals and their clients is possible. This imbalance of power rests, among other things, on the possession by professionals of specialised knowledge. ${ }^{44} \mathrm{Haug}^{18}$ pointed out as long ago as 1973 that the coming information revolution had significant implications for professionalism. By embracing the increased access to specialist knowledge for their patients that the internet brings, ${ }^{45}$ doctors have an opportunity to further increase trust and to provide their patients with the tools to truly hold them to account. If patients know that current medical knowledge advocates the aggressive management of blood pressure in those with diabetes, they can hold their doctor to account and engage in discussion about why their blood pressure has been ignored. This sharing of knowledge may build trust and so enhance true accountability. It does, however, bring with it significant problems; current average consultation lengths in both primary and secondary care in the UK leave little time for this kind of sharing.

\section{Accountability and "moral" motivation}

In seeking to define a route to improved accountability, it is also important to consider the factors that motivate individuals to perform as well as they can. Family doctors in the UK are accountable to the local NHS body (known as a primary care trust) that is responsible for the commissioning of services. This accountability occurs via the new appraisal system but, if asked, it is likely that practitioners would not list this as one of the things that motivates them. There is a danger that concentrating on technical accountability to those with powers of sanction and using mechanisms and measures that may not seem relevant to the world views of those being assessed will impact negatively upon "moral motivation". ${ }^{32}$ An editorial in the $B M J$ reflecting on the changes in regulation that followed some of the scandals discussed above concluded:

"The danger is, however, that it's all too much and too confused. Doctors in the UK] now face revalidation, compulsory continuing medical education and audit, governance of their clinical activity by their trust or primary care group, peer review, and a possible visit from a hit squad from their college or from the Commission for Health Improvement. The dangers are that their internal motivation (the most important thing) is crushed, that their time is diverted into activities that are more bureaucratic than beneficial to patients, and that they resort to game playing to buck the system (something at which doctors are highly skilled)."11

Lipsky, ${ }^{46}$ in a discussion of the work of public servants in the USA, contends that the imposition of performance management and rules in systems where resources are limited and objectives ambiguous runs the risk of inducing alienation among workers at the front line. This alienation may lead to a rigid adherence to rules that is not always appropriate. After studies in a variety of public service contexts, Lipsky embraces trust rather than confidence as the way forward (although he does not use these precise terms); he concludes that the best defence against this kind of demoralisation and the dysfunctional consequences of an over-literal interpretation of rules is an increase in professionalism and the internal motivation that goes along with it. The challenge is to find a form of professionalism that is prepared to open itself to scrutiny and, through openness, allow trust to develop.

\section{CONCLUSION}

We have argued that some governments, particularly that in the UK, have responded to a perceived crisis of trust in health services by embracing a model of regulation based on building confidence in institutions via rules and structures rather than seeking to maximise trust. While recognising that a response is necessary to the problems that have occurred in 


\section{Key messages}

- Current policy measures designed to improve quality of health care in the UK are aimed at increasing confidence by the use of rules and surveillance.

- This approach may actually reduce trust between doctors and their patients.

- Transparency about the conflicts that arise as a result of the duty on professionals to be accountable to more than one audience should be explored as a means of increasing trust.

- Openness and transparency should form the basis of the relationship between individual doctors and their patients if trust is to be re-established and quality of care improved.

healthcare systems across the world, we believe that this approach carries with it significant risks. In seeking alternative solutions we have looked at the concept of accountability, both in terms of the potential audience ("to whom") and the possible sanctions that they might apply ("held to" account), as well as arguing for attention to be paid to the type of account that is rendered. It is easy to call for transparency as a means of holding healthcare providers to account, and the UK government has used its league tables and star systems in this way in the pursuit of greater confidence in institutions. We argue that such outcome related systems are potentially open both to gaming by those being assessed and to political manipulation by those drawing up the tables, and may in practice act to decrease public confidence. Valuing trust above confidence and taking a more complex approach to transparency, sharing with the public the dilemmas faced when those delivering health care are accountable to multiple audiences, might offer a way forward. However, while involving the public in this way has been shown to be of value in small and specialised situations such as that exemplified by citizens' juries, its wider role in improving trust in delivering health care remains to be established.

We have also discussed what might be called trust at the micro level between individuals and practitioners. "Trust me, I'm a professional" is no longer tenable as a basis for medical practice. On the other hand, a professional ethic that embraces a more equal sharing of knowledge between professionals and their clients and that works towards a model of shared decision making will improve the ability of clients to hold their health professionals to account, while also acknowledging the essential uncertainty that makes trust necessary. The search for greater quality of care thus becomes a shared project between doctors and their patients, rather than a mechanistic application of some mythical "best way" embodied in a set of rules. Neglect of trust at the micro level by policy makers in favour of ever more complex measures to improve confidence runs the risk of damaging the internal ("moral") motivation of practitioners, with consequences that cannot be fully foreseen.

\section{Authors' affiliations}

K Checkland, M Marshall, National Primary Care Research and Development Centre, University of Manchester, Manchester, UK S Harrison, Department of Applied Social Science, University of Manchester, Manchester, UK

\section{REFERENCES}

1 Donaldson $\mathrm{U}$. Professional accountability in a changing world. Postgrad Med J 2001;77:65-7.
2 Allen P. Clinical governance in primary care: accountability for clinical governance: developing collective responsibility for quality in primary care. BMJ 2000;321:608-11.

3 Mudur G. Indian doctors not accountable, says consumer report. BMJ 2000;321:588.

4 Sheldon T. Dutch hospitals should be more accountable, says report. BMJ 2002;324:68b.

5 Woods D. Epidemic of care: a call for safer, better, and more accountable health care. BMJ 2003;327:109.

6 Davies H. Falling public trust in health services: implications for accountability. $J$ Health Serv Res Policy 1999;4:193-4.

7 Foster P, Wilding P. Whither welfare professionalism? Soc Policy Admin 2000;34:143-59.

8 Weiss M, Fitzpatrick R. Challenges to medicine: the case of prescribing. Sociol Health Illness 1997; 19:297-327.

9 McKinlay JB, Marceau LD. The end of the golden age of doctoring. Int J Health Serv 2002;32:379-416.

10 Beck U. Risk society: towards a new modernity. London: Sage, 1992.

11 Smith R. Regulation of doctors and the Bristol inquiry. BMJ 1998;317:1539-40.

12 Marshall MN, Braspenning J. European family practice and public accountability. Fam Pract 2001;18:473-4.

13 Davies HTO, Shields AV. Public trust and accountability for clinical performance: lessons from the national press reportage of the Bristol hearing. J Eval Clin Pract 1999;5:335-42.

14 Bauchner $\mathrm{H}$, Vinci R. What have we learnt from the Alder Hey affair? BMJ 2001;322:309-10.

15 Dalrymple T. Shipman trial: special report. The Guardian 2 February 2000.

16 O'Neill B. Doctor as murderer. BMJ 2000;320:329-30.

17 Dyer 0 . Shipman murdered more than 200 patients, inquiry finds. BMJ 2002;325:181a.

18 Haug MR. Deprofessionalization:; an alternative hypothesis for the future. In: Halmos P, ed. Professionalism and social change. Keele: University of Keele, 1973.

19 Department of Health. The new NHS: modern, dependable. London: The Stationery Office, 1997.

20 Department of Health. A first class service: quality in the NHS. London: The Stationery Office, 1998.

21 Department of Health. Information for health: an information strategy for the modern NHS 1998-2005. London: The Stationery Office, 1998.

22 Department of Health. The NHS plan: a plan for investment, a plan for reform. London: The Stationery Office, 2000.

23 Department of Health. Clinical governance: quality in the new NHS. London: The Stationery Office, 1999.

24 Scally G, Donaldson $\sqcup$. Looking forward: clinical governance and the drive for quality improvement in the new NHS in England. BMJ 1998;317:61-5.

25 Loughlin M. 'Quality' and 'excellence': meaning versus rhetoric. In: Miles A, Hampton JR, Hurwitz B, eds. NICE, CHI and the NHS reforms: enabling excellence or imposing control? London: Aesculapius Medical Press, 2000.

26 Loughlin M. On the buzzword approach to policy formation. J Eval Clin Pract 2002;8:229-42.

27 Goodman NW. Clinical governance. BMJ 1998;317:1725-7.

28 Goodman NW. Clinical governance: vision or mirage? J Eval Clin Pract 2002;8:243-9.

29 Schon D. The reflective practitioner: how professionals think in action. Aldershot: Avebury, 1983.

30 Rawlins M. In pursuit of quality: the National Institute for Clinical Excellence. Lancet 1999;353:1079-82

31 Smith C. Trust and confidence: possibilities for social work in 'high modernity'. Br J Soc Work 2001;31:287-305.

32 Harrison S, Smith C. Trust and moral motivation: redundant resources in health and social care? Policy and Politics 2004 (in press).

33 Harrison S, Smith C. Neo-bureaucracy and public management: the case of medicine in the National Health Service. Competition and Change 2004 (in press).

34 O'Neill O. A question of trust: the BBC Reith Lectures 2002. Cambridge: Cambridge University Press, 2002.

35 Carvel J. Hospital targets hit - then missed. The Guardian 3 June 2003.

36 Power M. The audit society: rituals of verification. Oxford: Oxford University Press, 1997.

37 James A. Private firms could run NHS hospitals. The Guardian 19 December 2002.

38 Nutley SM, Smith PC. League tables for performance improvement in health care. J Health Serv Res Policy 1998;3:50.

39 Hadorn D, Holmes A. The New Zealand priority criteria project. In: New B, ed. Rationing: talk and action in healthcare. London: BMJ Publishing Group, 1997:183-201.

40 Coast J. Rationing within the NHS should be explicit: the case against. In: New B, ed. Rationing: talk and action in healthcare. London: BMJ Publishing Group, 1997:149-155.

41 Harrison S, Dowswell G. The selective use by NHS management of NICEpromulgated guidelines: a new and effective tool for systematic rationing of new therapies? In: Miles A, Hampton JR, Hurwitz B, eds. NICE, CHI and the NHS reforms: enabling excellence or imposing control? London: Aesculapius Medical Press, 2000.

42 Mort M, Harrison S, Dowswell T. Public health panels: influence at the margins? In: Kahn U, ed. Participation beyond the ballot box: European case-studies in state-citizen political dialogue. London: UCL Press, 1999. 
43 Lenaghan J. Rationing and rights in healthcare London: Institute of Public Policy Research, 1996.

44 Freidson E. Profession of medicine: a study of the sociology of applied knowledge. Chicago: University of Chicago Press, 1988.
45 Coiera E. The Internet's challenge to health care provision. BM 1996;312:3-4

46 Lipsky M. Street-level bureaucracy: dilemmas of the individual in public services. New York: Russell Sage Foundation, 1980.

\section{$\mathrm{ECHO}$}

\section{Safe surgery stops shunt infections}

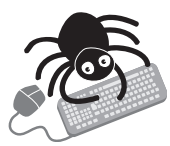

Please visit the Quality and Safety in Health Care website [www. qshc.com] for a link to the full text of this article. atients with hydrocephalus can be spared the devastating effects of infection after being fitted with drainage shunts, a study of more than 100 patients has shown.

In operations to 126 patients, covering 176 shunts over seven and a half years, only one shunt infection was recorded-and that seemed to originate from appendicitis progressing to peritonitis seven months after the operation.

This impressive record was attained by adopting a culture of zero tolerance to infection during the operations, with all staff strictly following detailed and rigorous preventive procedures based on asepsis, antisepsis, prophylactic antibiotic treatment, and-specifically-avoiding haematomas. The operations took place in one dedicated neurosurgery theatre with neurologically trained staff, where entry or exit during the procedure was permitted only in real emergency. All staff were fully gowned and masked, and the protocols went to great lengths to avoid infection from the surroundings, instruments, and implants. All operations were either performed by or closely supervised by the same senior neurosurgeon, and lapses in protocol were not tolerated.

The 126 patients were treated at the neurosurgical department of one UK hospital trust; 33 of them had revisions to implants fitted at other centres.

Reported mortality from shunt infections varies from 1.5 to $22 \%$, and infections occur in $5-5 \%$ of procedures, though rates as low as $0.3-5 \%$ have been reported. Infection is to be avoided at all costs as survivors can have severely impaired mental and neurological functions, but other studies of how to do so have been inconclusive.

A Journal of Neurology, Neurosurgery, and Psychiatry 2004;75:87-91. 